This item was submitted to Loughborough's Research Repository by the author.

Items in Figshare are protected by copyright, with all rights reserved, unless otherwise indicated.

\title{
Applying HRO and resilience engineering to construction: Barriers and opportunities
}

PLEASE CITE THE PUBLISHED VERSION

http://dx.doi.org/10.1016/j.ssci.2016.08.019

PUBLISHER

(C) Elsevier

VERSION

AM (Accepted Manuscript)

\section{PUBLISHER STATEMENT}

This work is made available according to the conditions of the Creative Commons Attribution-NonCommercialNoDerivatives 4.0 International (CC BY-NC-ND 4.0) licence. Full details of this licence are available at: https://creativecommons.org/licenses/by-nc-nd/4.0/

\section{LICENCE}

CC BY-NC-ND 4.0

\section{REPOSITORY RECORD}

Harvey, Eleanor, Patrick Waterson, and Andrew R.J. Dainty. 2019. "Applying HRO and Resilience Engineering to Construction: Barriers and Opportunities”. figshare. https://hdl.handle.net/2134/22429. 


\section{Applying HRO and Resilience Engineering to Construction: Barriers and Opportunities}

Eleanor J. Harvey Human Factors and Complex Systems Research Group. Loughborough University, Loughborough, Leicestershire, LE11 3TU, UK. E.J.Harvey@lboro.ac.uk

Patrick Waterson Human Factors and Complex Systems Research Group, Loughborough University, Loughborough, Leicestershire, LE11 3TU, UK. P.Waterson@1boro.ac.uk

Andrew R. J. Dainty School of Civil and Building Engineering, Loughborough University, Loughborough, Leicestershire, LE11 3TU, UK. A.R.J.Dainty@lboro.ac.uk

High reliability organising $(H R O)$ and resilience engineering $(R E)$ have emerged as key concepts in safety management which promise a move away from bureaucracy and a means to manage safety without sacrificing performance. However, attempts to apply these ideas outside the ultra-safe sectors within which they developed have so far been limited. This paper uses the construction industry as a test case to explore the applicability of HRO and RE in a less highly regulated context. Through this discussion the research gaps are highlighted which have prevented the expansion of these new approaches into new sectors. The project-based nature, transient workforce, widespread outsourcing of labour and financial pressure of the construction sector limit opportunities for investment in employees and learning from experience; hence, developing principles advocated by HRO and RE such as management commitment, sensitivity to the frontline, prioritisation of safety, empowerment of employees, and a just culture presents a significant challenge. In spite of these barriers, there are also opportunities to be considered for construction to incorporate aspects of $H R O$ and RE at an employee-centred level rather than organisational: Aspects of mindfulness and imagination; RE's progressive understanding of accidents; and its holistic approach to cultivating resilience. It is argued that these opportunities offer a useful perspective for reframing safety debates in construction. The paper concludes with a research agenda which puts forward the need to extend and adapt aspects of HRO and RE in order to tackle some of the key characteristics of construction, namely subcontractor networks and temporary projects.

Key words: Complex systems, construction, high reliability organising, human factors, resilience engineering 


\section{Introduction}

In the UK, $31 \%$ of all fatal occupational injuries were from the construction sector (HSE, 2014), significantly above the average for all industries. The same is also true in the US where 18.9\% (NIOSH, 2011) and Australia where 13.6\% (SWA, 2015) of occupational fatalities occurred in construction. There is a pressing need to challenge the widespread perception that that risk is an inherent part of construction work and safety management is a "bureaucratic burden" that detracts from production (Swuste et al., 2012, p. 1333). So-called "safety inflation" (p.251) has resulted in cynicism. Occupational safety and health (OSH) has become about protecting vested interests, shirking responsibility, enhancing company image, and reducing common sense (Brown and Hanlon, 2014). It has become an increasingly bureaucratic exercise (Dekker, 2014) as organisations find security in copious, complicated documentation instead of valid risk analysis (so called 'paper safety' - Haddon-Cave, 2009).

Borys et al.'s (2009) adaptive age of safety incorporates emerging fields of high reliability organising (HRO) and resilience engineering (RE) which represent a significant change in the way safety is addressed. They embrace the notion that, although many accidents are attributed to human error, the human capability for adaptation is also the element of a system which enables it to sustain reliable performance in light of adversity. HRO and RE may have developed in different fields, but both have arisen in response to the growing complexity of systems and the limitations of safety management systems (SMS) to protect the workforce. This age promises a move away from bureaucracy and regulation in safety; an understanding of accidents that does not rely on a root cause; and a way to manage the conflict between productivity and safety - all of which hinder OSH management in construction. Construction is a particularly unique industry: It has been characterised as an organic (Lingard and Rowlinson, 2005), heterogeneous network of subcontractors who form temporary multiple organisations (TMOs) (Stringer, 1967) to produce often unique projects.

It might be assumed that new approaches which promise to reduce paperwork and regulation would be welcomed within construction, however, the sector has remained largely untouched by RE or HRO, and little is known about generalising these theories outside the safety-critical sectors in which they developed (HSE, 2011). Contrasting construction with the environments in which HRO and RE have previously been studied (organisations with permanent, stable structures and a clear purpose) provides an interesting lens through which to explore their potential and how these theories would need to be adapted to fit another context. 
Accordingly, this review evaluates the extent to which these theories are compatible with the construction sector in a discursive essay, contrasting the characteristics of construction with the principles of HRO and RE. Section 2 introduces HRO and RE, looks at why and how they arose, where they fit within the existing landscape of safety research, and the gaps in construction safety which these new approaches could provide fresh insight into. Section 3 uses construction as a test case to explore the challenges of implementing HRO and RE and identify opportunities where elements of these concepts - their approach to risk management (Section 3.1), organisational principles (Section 3.2), and employee-centred principles (Section 3.3) - could be applied or adapted to improve safety in this sector. In doing so it puts forward the impediments to the adaptive age taking hold in other high-risk, but not necessarily safety-critical, sectors. 


\section{Safety in the Adaptive Age and in Construction}

The differences between HRO and RE are subtle and there is an ongoing discourse as to whether the more recent of the two (RE) is simply a rebranding of the more established school of HRO. This section explores the origins of HRO and RE, unpacking their different philosophies and metrics, alongside the current state of safety research in construction to show how these nascent fields have diverged from traditional OSH.

Since the introduction of the health and safety at work act (HSW) (SI 1974/1439), the past 40 years have seen devolution of OSH - shifting responsibility from the government's factory acts, to organisational SMS, to teams within organisations. Safety has been described as progressing through a series of ages, each distinguished by its emphasis on different aspects of the system. There are multiple accounts of these ages: Hale and Hovden (1998) proposed a technical age, human factors (HF) age, and management systems age; while Reason (1997) the person, engineering, and organisational safety models; and Hudson (2007) waves of technology, systems, and culture.

Most recently, the adaptive age (Borys et al., 2009) has seen principles HRO and RE emerge within OSH management. These five ages are illustrated alongside the associated safety approaches in the timeline in Figure 1. 


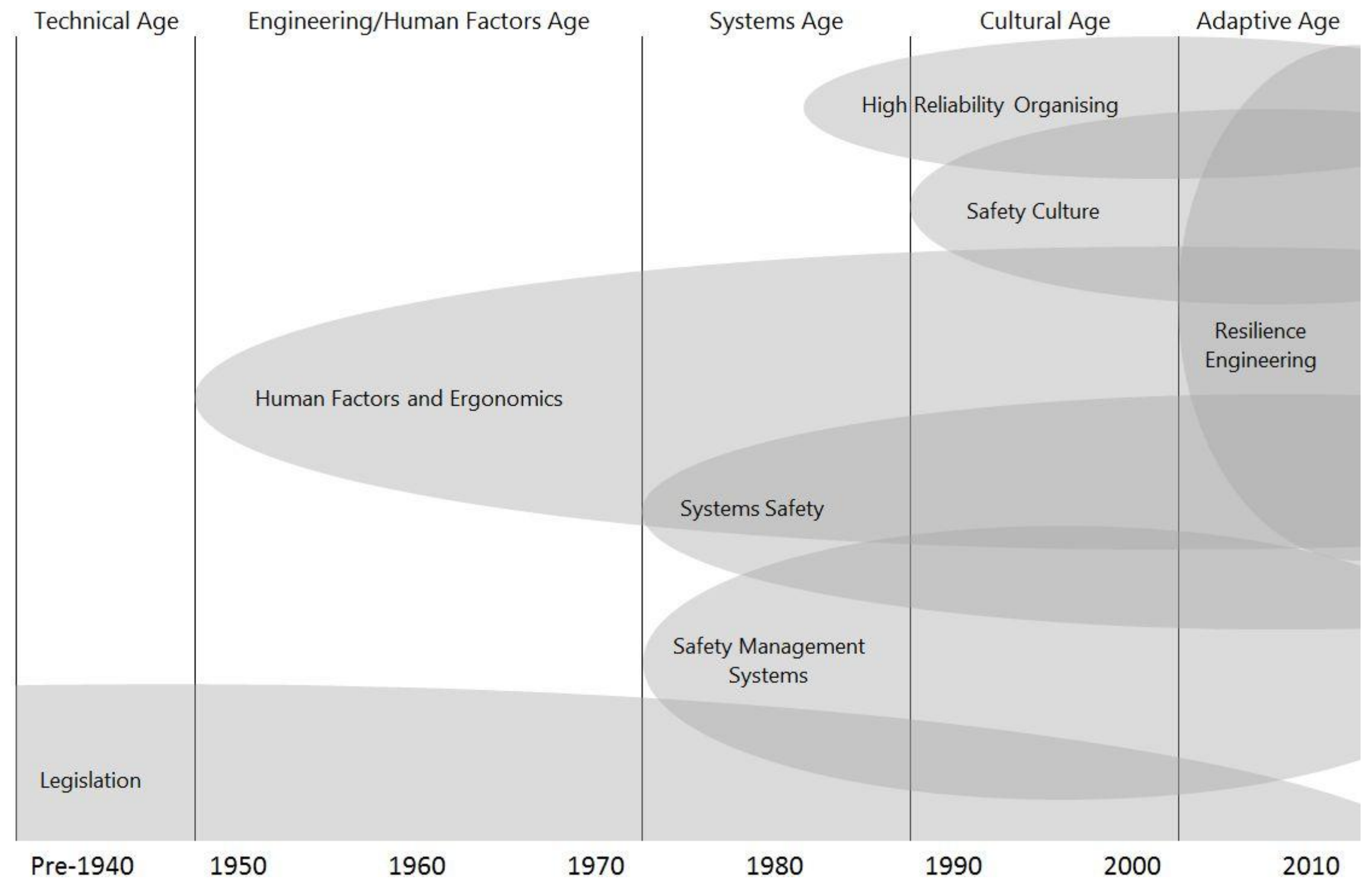

Figure 1 - A timeline illustrating the ages of safety based on Waterson et al.,(2015) 
Although OSH has developed at different times in different industries, Reason (1997), Hale and Hovden (1998), and Hudson's (2007) accounts are broadly in agreement that its focus has moved from the individual interactions between people and technology to a holistic systems approach. OSH management in construction has followed the same overall trend, but has arguably been slower than other sectors in being shaped by the paradigms of the adaptive age, and to some extent the systems and cultural ages too. The first academic studies in construction safety emerged as late as 1978, and focused on technical aspects - accident statistics, causes, and costs. From 2002 research diversified to explore individual factors such as behaviour, competence and attitude, and most recently organisational characteristics, relationships, and culture (Zhou et al., 2015).

Some studies have demonstrated the value of a systemic approach in construction. Organisational factors have been shown to reduce unsafe behaviours more than proximal factors such as site condition, materials, equipment and individual characteristics (Haslam et al., 2005; Khosravi and Bastani, 2014). However, in terms of successful interventions to prevent fatal injuries in construction sites, a recent review (van der Molen et al., 2012) concluded that regulation, training, inspections, and occupational health services are ineffective. Safety culture has also struggled to establish itself as a research topic in construction, emerging later than in other industries and declining since 2008 (Zhou et al., 2015). To move forward, the differences between construction and organisations where HRO and RE have been successfully applied need to be understood.

\subsection{Comparing the Origins of $\mathrm{HRO}$ and RE}

HRO developed in response to normal accident theory (NAT) (Perrow, 1984), demonstrating that it is possible for some organisations to avoid 'inevitable' accidents. By observing organisations which operate successfully in "unforgiving environments" (Weick and Sutcliffe, 2007, p. 164) (aircraft carriers, air traffic control, and a nuclear power plant) the qualities of organisational mindfulness, which enable these systems to cope, were identified. Case studies have shown that high reliability organisations are characterised by their capacity to respond, learn, and feedback quickly through accurate communications, and their flexibility to improvise by recombining resources, skills and experience (Weick and Sutcliffe, 2007). These traits demonstrate the presence of organisational mindfulness - "a rich awareness of discriminatory detail and a capacity for action" (Weick et al., 2008, p. 37) which enables HROs to notice the unexpected developing, contain it, or act resiliently in the 
face of it. Theoretically, HROs respond to perturbations in ways that strengthen adaptability increasing learning, flexibility, experience - rather than reducing it by adding further controls (Sutcliffe and Vogus, 2003).

One core principle of HRO is a 'commitment to resilience', a term which has recently appeared with increasing frequency in a variety of contexts - ecological, individual and engineering (Bhamra et al., 2011). Engineering resilience in relation to safety grew out of 'organisational resilience', a term which first appeared in Mallack (1998) and Horne and Orr (1998) who described the ability of an organisation to respond to change constructively, without introducing regression. RE has been described as the natural next step in OSH following a highly developed 'interdependent' (DuPont, 2015) or 'generative' (Westrum, 1991) safety culture, "to overcome the limitations of existing approaches" P.11 (Woods and Hollnagel, 2006). Its new perspective - seeing human adaptability as an asset - has been described as a significant step change (Hollnagel, 2008); however, it can also be seen as a continuation of the work of HF researchers to design systems around human attributes (Wilson, 2014). This emerging field has yet to develop a clear definition of its theory and limits making it difficult to draw comparisons with the clear framework of HRO. As such, Figure 1 shows RE overlapping several other safety approaches, representing that, although it represents change in philosophy. the field has yet to develop its own methods that can 'engineer' resilience.

\subsection{Comparing the Conceptual Underpinnings of HRO and RE}

In spite of their different origins, there are similarities between HRO and RE. Both emerged in response to the limitations of procedures and regulation to manage safety in complex systems, and both emphasise the human attributes - adaptability, imagination, mindfulness which enable people act resiliently and perform in circumstances where failure is expected. However, attempts to reconcile HRO with other high-risk safety approaches under the umbrella of 'resilience engineering' (Hollnagel et al., 2006) have had limited success because of their different philosophical foundations.

One explanation for this disparity is their differing perspectives on what constitutes organisational resilience. In HRO's model of organisational mindfulness, 'commitment to resilience' is categorised as a principle of containment, not anticipation. 'Firefighting' (reacting to emergencies as they arise) in high reliability organisations is seen as a positive trait and evidence of resilience (Weick and Sutcliffe, 2007) - something which, in other 
organisations, is seen as a symptom of poor planning and reactive management. Resilience engineers do refer to the work of HRO-scholars (Hollnagel, 2014), incorporating organisational mindfulness, whether or not this is true to Weick's original concept, as one part of RE's toolset of safety measures which can "facilitate the emergence of resilience" (Hollnagel and Sundström, 2006). Within RE resilience forms part of both anticipation and response - intrinsically linked as organisations adjust "prior to, during, or following changes" P.13 (Hollnagel and Fujita, 2013), whilst in HRO resilience is seen as the reaction to an incident, with a greater emphasis on 'bouncing back'.

\subsection{Comparing Validation and Measurement in HRO and RE}

In terms of auditing resilience and HRO, measurement scales for HRO have been developed (Vogus and Sutcliffe, 2007), but a literature review by the Health and Safety Executive (HSE, 2011) criticised the lack of quantitative evidence supporting the predictive validity of organising in this way and safety performance. The majority of research was said to be observational and qualitative, providing rich descriptions of the qualities of these organisations, but lacking a theoretical framework to justify why HROs succeed where other organisations fail.

Similarly for RE, research is needed in terms of real-world empirical methods to validate its constructs (Burnard and Bhamra, 2011; Sutcliffe and Vogus, 2003), especially as these are still developing. Hollnagel and Woods (2006) state that resilience cannot be measured, only an organisation's capacity for it through variables such as buffering capacity, the flexibility of its structure, awareness of proximity to margins, and tolerances enabling graceful degradation (Woods, 2006). The characteristics of a resilient organisation are less well-defined than high reliability organisations, but the RE community believes any organisation can become resilient, with different industries managing stability and flexibility in different ways (McDonald, 2006). Therefore, RE could offer valuable opportunities to expand the wellintentioned ideas of HRO to suit other contexts, but as yet further work is needed to understand the factors that facilitate the development of both resilience and mindfulness. 


\section{Contrasting HRO and RE within Construction}

The following sections will compare concepts of HRO and RE through the lens of the construction industry and focus on three themes: Their approach to risk management, characteristics of the organisation, and employees which contribute to resilience and highreliability. Each theme will be discussed first in relation to the differences between these adaptive age approaches and construction OSH which present barriers to their implementation, followed by the opportunities where their concepts could be valuable.

\subsection{Risk Management}

\section{Barriers}

\section{Applicability to construction}

One of the greatest barriers to adopting HRO in new sectors is the belief that HRO is only applicable in safety critical industries. In construction, workers believe that "safety detracts from the primary production process" (Swuste et al., 2012, p. 1333). This is true in some sectors such as rail, where unforeseen hazards frequently lead to delays or cancelations (Hale and Heijer, 2006a); however, both RE and HRO emphasise maintaining performance and safety simultaneously - the key to safe performance without sacrificing reliability is resilience. Reason's Organisational safety model deliberately blurs the line between quality and safety, as safe operation is an integral part of performance as a whole (Reason, 1997). This is particularly true in the safety-critical industries where HRO developed. The synonymous use of "safe" and "reliable" implies high-reliability is only attainable by organisations where safety is the primary focus - a view which underlies the conceptual barrier to applying this theory elsewhere and one which has kept HRO from integrating into construction (olde Scholtenhuis and Dorée, 2014). However, Weick and Sutcliffe (2007) intend their work as a template for "any institution that wants to better organise for high reliability".

Neither HRO nor RE promise zero accidents, but rather a reduced probability in terms of the number of encounters. In circumstances where the risks are high, it is possible for an organisation to be described as resilient even if it has accidents (Hollnagel, 2014). Similarly, if the risks are low, an organisation may be safe without needing to be resilient (Hale and Heijer, 2006b). The high number and type of accidents faced by construction compared to ultra-safe organisations may explain one of the differences that prevent HRO and RE being applied more widely. Although construction is high-risk, the concern here is the high level of personal injury incidents, whereas HRO and RE have developed in safety-critical sectors - 
such as nuclear and aviation - with the potential to cause harm to third parties (Reason, 1997). The prevalent causes of death in construction are falls from a height (30\%), slips, trips and falls on the level, being struck by a moving vehicle (Haslam et al., 2005) and electrocution (HSE, 2014).

Accidents therefore become intolerable on account of their consequences rather than their frequency...100 isolated, singular deaths may have far less emotional impact than 10 deaths in a single event. (Amalberti, 2006, p. 269)

The social amplification of risk framework (SARF) describes how some risks are amplified by social, psychological, and cultural factors (Kasperson et al., 1988). Although the majority of occupational fatalities occur due to construction accidents, they are "isolated" events, so the risk is socially "attenuated" and research has been diverted to focus on sectors with greater risk of harm to the public and which generate more political and media interest. However, construction is not immune to causing collateral deaths: Last year, 4 passers-by died in UK construction accidents (HSE, 2014) and the collapse of the Rana Plaza textile factory in Savar, Bangladesh in 2013 killed 1,134 people (The Guardian, 2015). Reason (1997) argues risks to third parties are high across all sectors because, despite differences at the frontline, they are equally threatened by latent problems of planning, scheduling, and budgeting which contribute to major accidents. For HRO and RE to benefit construction, the similarities between accidents in safety critical sectors and those in construction need to be embraced.

\section{Opportunities}

\section{Accident Causation}

Before the age of systems safety, accidents were believed to have a root cause - a technical malfunction or individual failure on which events could be blamed. This simplistic model is emotionally satisfying and has legal and financial benefits (Reason, 1997), but can fail to appreciate the complex relationships between causes and consequences. Within construction this tendency towards simplifying situations to find a root cause can be seen in contemporary accidents (Clegg and Kreiner, 2014). The prominence of the 'Zero Accidents' discourse also confirms this model. Using propaganda to manipulate workers' attitude to safety demonstrates the belief that accidents could be prevented with more effort or care (Dekker, 2015). Swuste et al. (2012) argue a better understanding of causal chains is needed to improve construction safety; however, given the loosely coupled structure of construction 
organisations, it can be difficult to identify and learn from causal links and to accept a lack of accidents as proof of good practice (Clegg and Kreiner, 2014).

Accidents in HRO are described in causal terms, as the result of an unfortunate combination of a number of errors; hence, detecting failures as they develop through sensitivity to weak signals is advocated (Weick and Sutcliffe, 2007). However, this simplistic understanding of accidents has been criticised for endorsing the idea that accidents can be prevented by paying more 'mindful' attention to precursor events (HSE, 2011). Based on this interpretation, risk analysis depends upon the systematic identification of causal chains and implies safety is a static commodity that can be quantified, not a dynamic process. Projects, like those in construction, have been described as "drifting environments" (Kreiner, 1996, p. 335), where the outcome changes over time, thus RE's notion of drifting accidents offers a different perspective on accidents investigation (Hollnagel, 2009) which could be better suited to loosely coupled systems than exploring causal chains and looking for pivotal failures. For RE, safety is a dynamic process, human behaviour cannot be categorised in a bimodal way and the causes of accidents are far more subtle and complex - nothing worth reporting happens (Hollnagel, 2009). Instead, accidents are caused by an undetectable "drift into failure" (Hale and Heijer, 2006a, p. 37) which is a natural part of operations in resource-constrained environments.

RE scholars argue a causal model cannot cope with complex relationships (Hollnagel, 2009) and unexpected failures (Hollnagel, 2014) - only predictable cases where data can be reliably assessed - and is hindered by a form of confirmation bias Hollnagel calls 'What-You-LookFor-Is-What-You-Find' (WYLFIWYF) (Hollnagel, 2009). The efficiency thoroughness trade off (ETTO) principle (the tendency to sacrifice thoroughness for efficiency) is key to understanding the 'drift' that means failure can develop out of normal behaviour. Humans have a natural tendency towards efficiency (Hollnagel, 2009). Rational decision-making is also limited by context, subject to social and cultural factors (Perrow, 1984), and constrained by finite cognitive resources so people "muddle through" making what they perceive to be "sensible adjustments to cope with current and future situational demands" P.149 (Hollnagel, 2014). In many cases, this performance variability is a positive improvement, enabling more efficient ways of working, but the same variability can also lead to failures (Hollnagel, 2009).

RE incorporates the ETTO into its understanding of accident causation, recognising that people instinctively make sacrificing decisions, or trade-offs, to cope with pressure; 
thoroughness is sacrificed for efficiency, safety is sacrificed for production. Instead, it is proposed that accidents are caused by functional resonance - an unexpected combination of everyday performance variability, or "ETTOing", the consequences of which are emergent rather than resultant (Hollnagel, 2009).

Reanalysing construction accidents through the lens of RE's functional resonance could provide a different perspective. Although trading off safety for production can lead to accidents, understanding that the workforce's natural adaptability has the potential to strengthen the system, as well as weaken it, highlights the opportunity to harness for the benefit of safety. These theories of drift within performance and its effects, which can reverberate unpredictably throughout a system, present an interesting challenge to construction and HRO's interpretation of accidents. Both these fields subscribe to the notion that accidents can be predicted and therefore prevented by promoting greater attention - or the vision of "zero accidents" in construction. However, according to RE, it is the efficient decisions which prevent accidents and maintain performance every day, as well as cause them when performance drifts outside the acceptable tolerance.

\section{Anticipating Accidents}

Accidents in high reliability organisations are, by definition, extremely rare. They operate in environments which preclude learning by experimentation because of the dangers they face; therefore, little is said about how they learn from accidents. Instead, mindfulness encourages a focus on the present because - although past experience can be valuable - memory can draw attention away from current events and provoke generalised interpretations based on hindsight. This reactive approach to learning from accidents (or precursors of accidents), where feedback is immediately acted upon, could be beneficial in an industry like construction where factors needed for long-term learning - leadership, processes, infrastructure, communication, education and community (Chinowsky et al., 2007) - are hindered by the dynamic and fragmented nature of TMOs.

HRO's principle of 'preoccupation with failure' encourages members of the organisation to imagine potential mistakes, elaborate on near misses, and articulate the consequences however distressing - so mitigations can be expanded (Weick and Sutcliffe, 2007). Similarly, RE advocates the use of 'Second Stories' - looking for other potential outcomes of the events to avoid bias, hindsight, and oversimplification caused by knowing the real outcome (Hollnagel, 2014). It also warns of the dangers of "distancing through differencing" or the "it 
would never happen to us" attitude (Cook and Woods, 2006) meaning people fail to see the similarities between accidents in other organisations and events in their own, and therefore cannot learn from them. Both these theories have potential to enhance safety in construction.

Recently RE has put forward an approach to safety management known as "safety-II". Traditionally, safety ("safety-I") has focussed on what went wrong following an accident; but under safety-II, a greater emphasis on the aspects that contribute to normal performance is encouraged; in order to learn from events they need to be frequent enough to make generalisations. In complete contrast with HRO, which advocates seeing the unique nuances of every event (Weick and Sutcliffe, 2007), RE accepts that accidents are difficult to learn from because they are rare, poorly understood, and difficult to make generalisations about. Instead, investigating everyday successes - such as human adaptability and positive performance variability - can be seen as an investment in performance rather than safety (Hollnagel, 2014).

Accident research in construction, as well as many other sectors, is hindered by a mistaken belief that "the potential for learning is proportional to the severity of the incident" (Hollnagel, 2014, p. 160). Hence, accident investigation is often confined to serious and fatal accidents (Hinze et al., 2006). Although it would be difficult to justify a shift in focus away from accidents (as advocated in safety-II) when they are a frequent occurrence, understanding accidents as emergent consequences of adaptations required to cope with pressure could reduce the propensity for blame, creating a just culture as advocated by both HRO and RE, and open up opportunities to embrace workers' flexibility - seeing it as a form of resilience as opposed to disobedience.

Key differences between HRO and RE have been identified in their approach to risk management and their applicability to other contexts. Underpinning these differences is their understanding of the way in which accidents develop. HRO, like construction, takes a view that accidents are the result of a causal chain of errors, thus the precursors to accidents can be detected by paying mindful attention to cues in the present. RE is founded on the belief that accidents emerge from adaptations made to cope with pressure and the "drift" towards failure is unnoticeable. This disparity is reflected in the ways the two schools advocate anticipating accidents. 
Table 1 lists the new concepts for risk management from the adaptive age, whether they arose from $\mathrm{HRO}$ or RE, and summarises the positive and negative points from the evaluation of their potential application in construction. 
Table 1 - Summary of barriers and opportunities for applying adaptive risk management characteristics in construction

\begin{tabular}{|c|c|c|c|}
\hline Risk management principle & From HRO or RE & $\begin{array}{c}\text { Barriers to application in } \\
\text { construction }\end{array}$ & $\begin{array}{c}\text { Opportunities for application in } \\
\text { construction }\end{array}$ \\
\hline $\begin{array}{l}\text { Applicable to safety-critical industries where } \\
\text { accidents are rare but catastrophic. }\end{array}$ & HRO & $\begin{array}{l}\text { Risks in construction are socially attenuated by } \\
\text { high frequency and low fatalities-per-accident. }\end{array}$ & \\
\hline $\begin{array}{l}\text { Understand failures as the undetectable } \\
\text { consequence of 'functional resonance' } \\
\text { (performance variability). }\end{array}$ & $\mathrm{RE}$ & $\begin{array}{l}\text { The zero accident discourse and a culture of } \\
\text { blame are prominent in construction, so } \\
\text { constructs that challenge this are unlikely to be } \\
\text { accepted. }\end{array}$ & $\begin{array}{l}\text { Could be better suited to a loosely coupled } \\
\text { industry where causal chains are difficult to } \\
\text { identify. } \\
\text { Could counteract confirmation bias and } \\
\text { propensity for blame when analysing accidents. }\end{array}$ \\
\hline $\begin{array}{l}\text { Accidents can be predicted and prevented by } \\
\text { paying greater attention to precursors. }\end{array}$ & $\mathrm{HRO}$ & $\begin{array}{l}\text { Causal chains are difficult to identify in loosely } \\
\text { coupled systems. } \\
\text { Implies workers are lazy, negligent, or careless. }\end{array}$ & $\begin{array}{l}\text { Could build upon 'zero accidents' which is } \\
\text { popular in construction. }\end{array}$ \\
\hline Focus on everyday performance. & $\mathrm{RE}$ & $\begin{array}{l}\text { Difficult to justify when accidents are a } \\
\text { frequent occurrence. }\end{array}$ & $\begin{array}{l}\text { Could promote sensitivity to operations. } \\
\text { Could enable investment in performance and } \\
\text { strengthening the positive aspects of a system, } \\
\text { rather than preventive methods. }\end{array}$ \\
\hline $\begin{array}{l}\text { Focus on the present when responding to } \\
\text { unexpected events. }\end{array}$ & $\mathrm{HRO}$ & & $\begin{array}{l}\text { Could reduce the requirement for long-term } \\
\text { learning in a temporary organisation. }\end{array}$ \\
\hline
\end{tabular}




\subsection{Organisational Principles}

\section{Barriers}

\section{Applicability to construction}

As with its theories about risk management, HRO's ideas about organisations have also meant it has not been readily embraced by construction. The type of organisation HRO is based upon is fundamentally different from construction work. NAT (Perrow, 1984) arranges organisations onto two axes, forming 4 quadrants, according to their characteristics. "Coupling" (originally an engineering term) describes the capacity to absorb shocks and failures. If an organisation is tightly coupled its processes are time-dependent, sequential and invariable - leaving little slack - so perturbations have a rapid impact. "Complexity" describes the interactions between components. In linear systems it is easier to substitute people and materials because roles are less specialised, information is directly monitored, feedback is local, and control can be decentralised. In complex systems the interactions may be invisible, unpredictable, indirectly measured, and connect multiple subsystems; therefore, perturbations have a widespread impact.

In organisations which are both tightly coupled and complex failures have a rapid and widespread impact. HRO describes the characteristics needed for safe performance in this type of organisation. According to the NAT framework, construction is low risk because raw materials are assembled, rather than fabricated, and their processes are visible and can be understood; thus there are opportunities to learn from construction accidents. However, the growing popularity of megaprojects as a delivery model for public services (Flyvbjerg, 2014) means managers must coordinate numerous subcontractor organisations, work to a tight schedule, and keep agreements with local stakeholders to minimise disruption. For example, details such as the sequence in which deliveries have been loaded onto a lorry can mean a delay of a few hours but have widespread repercussions over several months for multiple other contractors who cannot begin their work until prerequisite stages have been built (Walsh, 2015). Although the industry as a whole is loosely coupled, projects and their supply chains have become increasingly tightly coupled and complex - a structure which Dubois and Gadde (2002) describe as a two-layered pattern of coupling. In light of the recent changes to the industry, the applicability of HRO's principles in construction needs further consideration. 


\section{Structure}

Under normal conditions high reliability organisations have an extremely hierarchical structure with clear roles and responsibilities; redundancy; high levels of accountability, and expectations for following procedures and performance (Roberts and Rousseau, 1989). The paradox of achieving high reliability is creating a strong hierarchy which can be dissolved rapidly in the face of adversity, allowing its empowered employees to manage local events. This transformation from centralised to decentralised control is only possible if organisations initially have a centralised control hierarchy (Glendon et al., 2006). The importance of management has been well established in safety as a whole (Zohar, 2010). Particularly within $\mathrm{RE}$, the management's ability to diagnose potential problems, make-decisions, and act assertively, underpinned by their commitment (Flin, 2006) and individual resilience (Hollnagel, 2009) are all believed to contribute to resilient leadership among managers. In construction projects however, lines of authority and accountability become unclear due to the dynamic, transient nature of TMOs.

\section{Culture}

Developing adaptability through cultural change is an idea which has appeared in both HRO (Weick and Sutcliffe, 2007) and RE (Reason, 2000; Wrethall, 2006). A just or reporting culture (Reason, 1997) is required for 'sensitivity to operations' or understanding work as performed, not as imagined (Hollnagel and Woods, 2006; Wrethall, 2006). Construction, like many organisations, can be seen to take front line operations for granted. A recent inquiry exposed the practice of blacklisting construction workers for being vocal about OSH issues (House of Commons, 2015). It is an industry highly vulnerable to economic pressure, employment fluctuates with recession and growth, hence the use of contracting to provide flexibility of labour and meet changing market demands (Manu et al., 2013). It has been suggested that, because HRO developed in non-profit organisations where safety is a primary objective, its constructs would be difficult to implement in sectors, like construction, with conflicting goals and pressures (Tamuz and Harrison, 2006). A resilient response relies on contingency resources and experience within the workforce - a challenge in "stretched systems" (Hollnagel and Woods, 2006) when employees are viewed as a disposable commodity.

\section{Procedures}

Although HRO classifies resilience as a principle of containment, it is recognised that a resilient response depends upon the "structures that have been developed before crisis arrives" 
(Weick and Sutcliffe, 2007). Similarly in RE, maintaining control in the face of unexpected events depends upon both anticipation and response (Hollnagel and Fujita, 2013). In spite of this, both HRO and RE are sceptical of formal planning: The limitations of foresight mean planning can never anticipate all the ways a system could fail. Planning can reduce the capacity for a resilient response because it imposes expectations on situations, promotes confirmation bias, and reduces improvisation (Weick and Sutcliffe, 2007). RE also warns that an overemphasis on procedures could lead to "work-to-rule" where workers follow regulations so strictly it negatively impacts upon productivity and safety (Hollnagel, 2009).

Despite its limitations, RE recognises that in some cases proceduralisation may be the most appropriate safety mechanism (Amalberti, 2006). Perrow (1967) argues the degree to which organisational activity can be "pre-programmed" depends upon the activity itself. According to his framework, construction is classified as an industry well suited to procedures because its tasks are well structured and routine, exceptional cases are rare, and solutions to problems are easy to find. Thus, reducing proceduralisation is a concept from the adaptive age that should be applied with caution in construction. Avoiding planning may encourage resilience to develop in some organisations, but in others it could reduce anticipation and lead to reactive management (McDonald, 2006).

HRO recommends preparing for failure by building in contingency in the form of uncommitted resources or "pockets of resilience" P.80 (Weick and Sutcliffe, 2007). Rather than procedures or protocols, high reliability organisations plan by investing in systems that gracefully degrade and developing a broad range of employee experience; shared knowledge within the system; and training and drills to support 'deference to expertise'. In an industry like construction which is loosely regulated (Lingard and Rowlinson, 2005) and averse to rules (Swuste et al., 2012), formal contingency plans are difficult to establish. The notion of uncommitted resources to help manage unexpected events is attractive, but unlikely in such a resource constrained environment.

\section{Opportunities}

\section{Cultivating Resilience}

HRO's model of organisational mindfulness presents a 'one-size-fits-all' template which does not suit a fragmented, organic, transient organisation. However, RE recognises that "spontaneous resilience" (Amalberti, 2006, p. 271) can be found in unsafe systems; hence, its stance is a more inclusive and holistic one. Resilience is seen as an emergent property so a 
top-down approach - forcing systems to adopt structures seen in successful organisations shows an idealised understanding (Amalberti, 2006). A specific strategy for developing resilience is not prescribed; instead, RE methods should depend on the context and stage of development (McDonald, 2006).

RE relies on organisations learning from experience how best to facilitate resilience in their own operations. Resilience is expressed differently in each system and at each stage, so to develop it requires an ongoing commitment to identify and invest in the factors that contribute. In other words, resilience is a proactive process a system does, rather than - as HRO suggests - a reactive mechanism a system has (Woods and Hollnagel, 2006). This offers a more hopeful perspective, opening up the possibility of developing resilience in any organisation, providing the approach is suitable. The existing resilience within construction workers can be expanded to apply to safety, as well as production, without needing to adopt the structures of HROs; However, developing a strategy for cultivating resilience in a TMO where feedback loops are not well defined and learning from experience difficult - is an area in need of further research.

At an organisational level, the services within which HRO and RE have so far been studied shed little light on how adaptive safety might apply in a temporary project. Hierarchy, commitment to the workforce, reduced proceduralisation, and an unchallenged commitment of resources to safety are all concepts which do not transfer well into construction. However, it may be possible for construction to draw upon RE as its methods for 'engineering' resilience are not confined to a prescribed template and there is scope to develop a strand of RE specific to construction. Table 2 lists the organisational concepts for from the adaptive age, whether they arose from HRO or RE, and summarises the positive and negative points from the evaluation of their potential application in construction. 
Table 2 - Summary of barriers and opportunities for applying adaptive organisational principles in construction

\begin{tabular}{|c|c|c|c|}
\hline Organisational principle & From HRO or RE & $\begin{array}{l}\text { Barriers to application in } \\
\text { construction }\end{array}$ & $\begin{array}{c}\text { Opportunities for application in } \\
\text { construction }\end{array}$ \\
\hline
\end{tabular}

Applicable to complex and tightly coupled systems. is not seen as a high-risk industry despite the recent growth in complex projects.

Today's construction projects, which are far more complex and tightly coupled, indicate an opportunity to reconceptualise 'high-risk' industries.

Local-decision making and independence are encouraged.

Control is simultaneously centralised and decentralised.

HRO

Construction is loosely regulated.

Multiple subcontractors mean lines of authority and accountability are unclear.

Emphasis on zero accidents and identifying a

Just culture

HRO and RE

root cause of accidents.

Workers rarely report accidents and have been blacklisted for being vocal about OSH issues.

Resources are constrained due to economic

Prioritise and invest in safety

$\mathrm{HRO}$ and RE

Production is prioritised over safety.

Proceduralisation is widespread in construction due to the misconception that tasks are routine.

Avoid formal plans, and instead develop uncommitted contingency resources

HRO

Transfer of experience is limited between

temporary projects.

Resources are constrained due to economic pressure.

Production tends to be prioritised over safety.

Management commitment to the frontline

HRO and RE

Lines of authority and accountability are

unclear.

Cultivate resilience in a way appropriate to each context and stage

Highlights the need to focus research on developing a just culture in construction.
Further research is required to understand what

this looks like in organic TMOs.
Could open up the potential to develop

resilience in a new and different context. 


\subsection{Employee-centred Principles}

\section{Barriers}

\section{Empowerment}

At an individual level there are opportunities for employees to develop a resilient mind set which could allow construction to adopt adaptive safety in spite of the barriers at the organisational and risk management strategy levels. However, a significant discrepancy still exists with respect to their stance on empowerment. The challenge for tightly coupled and complexly interactive systems is the need for control to be simultaneously centralised - to see the interactions between different parts of the system - and decentralised - so operators can act quickly and independently (Perrow, 1984; Reason, 1997). Both HRO and RE advocate empowering individuals to respond to unexpected events, but decentralised decision-making applied in a context like construction - where safety is not prioritised, regulation loose, and lines of authority unclear - leads to workarounds, and unsafe acts.

Herzberg (1987) found that performance could be improved if employees had greater autonomy, direct feedback, and an understanding of the significance and identity of their task - unlike the fragmented tasks of scientific management (Taylor, 1911). To some extent this is similar to the principle of 'deference to expertise' in HRO (Weick and Sutcliffe, 2007) allowing leadership to migrate to the people with the most expertise, regardless of their rank or experience and RE which describes resilient organisations as "empowered to be independent, involved, informed, and informative" P.324 (Hollnagel and Woods, 2006). Weick and Sutcliffe (2007) say empowerment can be achieved by encouraging constant interaction between teams. Multi-disciplinary teams increase trust, prevent power struggles, and are better at coping because existing skills and knowledge can be recombined to deal with unique situations. They have greater diversity in their experiences - which can also be achieved through selection, job rotation, retraining - to increase awareness of the operational picture and prevent complacency. However, this is difficult in construction because the majority of work is subcontracted, allowing firms to employ specialists on a flexible basis. As a result, the organisation becomes fragmented into units with conflicting interests, ambiguous responsibilities, inadequate communication, and reduced teamwork (Manu et al., 2013).

An empowered workforce relies on communication, knowledge management, and opportunities for long-term investment and training, all of which are compromised in construction. To achieve the multi-skilled, self-managed teams seen in HROs, construction 
workers would need to be better educated and have higher expectations for job enrichment (Price et al., 2004). The existing literature on empowerment focuses on internal teams, and there is a lack of guidance as to how these could apply to outsource providers, highlighting a barrier to applying HRO to construction. For a TMO to empower employees in this way may not be possible, given that workers are employed for their specific skills, but it stresses the need to foster relationships between contractor organisations to create a community of practice with a better understanding of the "big picture".

\section{Opportunities}

\section{Sensitive to the Unexpected}

Under the principle of 'reluctance to simplify', HROs encourage an understanding of error which sees the unique nuances of suspicious events to learn more rather than generalise about them. Their tendency towards efficiency means people are quick to name, categorise and stereotype phenomena; this helps to organise information and make it more sharable, but the use of rigid categories can mean its thorough exploration is brought to a premature end. Avoiding simple diagnoses based on superficial similarities affords HROs a clearer and more complete picture of situations (Weick and Sutcliffe, 2007).

In intractable, high-risk environments it is impractical to be this thorough. Another concept proposed by Weick is that of "sensemaking", describing how people cope with ambiguity by making sense of a situation through action and communication, and settle for a plausible explanation (Weick et al., 2012). This is similar to RE's ETTO: Rather than counteracting the natural tendency to simplify, the ETTO accepts that it is impossible for people find thorough, rational explanations for every event. To cope in dynamic situations people have learned to trade off thoroughness for efficiency and identify all the relevant information without being overwhelmed, rather than "find the perfect response when it is too late." (Hollnagel, 2009, p. 55). HRO's sensemaking and RE's ETTO both describe the reality of coping with pressure in high-risk, ambiguous environments. Efficient or plausible explanations, rather than a complete understanding, can result in presumptuous decisions and lead to errors. Although it is impossible to avoid some simplification and routine, HRO's warning that this should be done "slowly, reluctantly, mindfully" (Weick and Sutcliffe, 2007, p. 12) is nonetheless a valuable message and one that has not gone unrecognised in construction: Clegg and Kreiner (2014) suggest that one way to improve learning from construction accidents is to "make learning harder, not to facilitate it". Where situations are complex and ambiguous, doubt and scepticism should be welcomed as they prevent complacency. 


\section{Imagination to Anticipate}

To avoid accidents, employees of high reliability organisations consciously maintain failure at the forefront of their mindset - the principle of 'preoccupation with failure'. HRO warns of the dangers of falling into automatic processing, and instead these organisations "persuade all their members to be chronically concerned about the unexpected" P.62 (Weick and Sutcliffe, 2007, p. 62). Reporting is rewarded and a questioning attitude encouraged so employees remain sensitive to weak signals - acting on hunches that something might be going wrong. The same concept can be seen in RE, as Hollnagel and Woods (2006) also advocate a “constant sense of unease” P.355 and Dekker "keeping the discussion on safety alive even when everything looks safe" (2006).

A similar concept has also been called "requisite imagination" (RI) (Adamski and Westrum, 2003, p. 193), "safety imagination" (Pidgeon and O'Leary 2000), and "chronic unease" (Reason, 1997). RI - "the fine art of anticipating what might go wrong” (Adamski and Westrum, 2003, p. 193) - is essential for resilience (Hollnagel and Woods, 2006); It fuels a questioning attitude and enables designers to anticipate all the possible scenarios. Similarly, safety imagination (Pidgeon and O’Leary, 2000) encourages a less rigid approach to anticipation in order to capture the failures outside expectations (Pidgeon, 2010). Finally, chronic unease was first described by Reason (1997) as "the assumption that every day will be a bad day" and has more recently been broken down into five attributes - vigilance, pessimism, RI, flexible thinking, and the propensity to worry (Fruhen et al., 2013).

Developing a culture of chronic concern about safety issues is a fundamental part of resilience and organisational mindfulness, and its potential to improve safety in construction has been recognised - "we need more theorising and imagination than facts and evidence" P.143 (Kreiner, 2009). Mentally simulating the potential ways the operations could fail expands the "complex tree of causalities" P.142 (Kreiner, 2009) therefore increasing the number of precautions to be taken. Imagination also extends the potential of learning from accidents using imagination to avoid what Cook and Woods (2006) called "distancing through differencing", and prevents "overlearning" from single-events by mediating experiences with an awareness of their complexity, randomness and ambiguity. In a masculine industry (Aulich, 2013; Lindebaum and Fielden, 2010) where risk as an integral part of work (Swuste et al., 2012), encouraging vigilance and lowering risk tolerance in this way presents an interesting opportunity. However, other than raising awareness that bringing attention back onto task when distracted requires conscious effort (Weick and Sutcliffe, 
2007), neither RE or HRO offer any empirical insights into how this 'preoccupation with failure' can be established or measured.

\section{Initiative to respond}

Their ability to transform between centralised and decentralised control means HROs could be described as both 'mechanistic' and 'organic' (Burns and Stalker, 1961). Organic industries respond rapidly to changing market conditions, whereas mechanistic organisations, such as process industries, have a stable hierarchy. Construction is organic which provides one explanation for its poor safety record. OSH is far more difficult to implement in organic organisations than mechanistic because autonomy, responsibility, and the use of initiative to overcome problems are encouraged (Lingard and Rowlinson, 2005).

In accordance with its philosophy that accidents can be detected as they develop, HRO encourages organisations to react to unexpected events with a contingency of uncommitted resources and diverse skills (Weick and Sutcliffe, 2007). Ironically, construction workers are adaptable - using initiative to work independently - but without clear lines of authority, regulation, and prioritisation of safety, the natural human tendency towards efficiency leads to unsafe workarounds and violations rather than resilient performance adaptations. This suggests high-reliability results from the combination of individual empowerment and hierarchical control. Therefore, for construction to be highly-reliable would require structural changes to improve regulation and management - an impossible challenge to implement given that construction projects are formed of multiple, temporary subcontractors (Stringer, 1967). Imposing control and structure in this way is a major barrier to expanding HRO to other sectors, but cultivating workers' "spontaneous resilience" and channelling this capability towards safety, rather than productivity, could provide a useful opportunity. In contexts like construction, with complex organisational networks and high pressure, workerinnovated practices have been shown to be more influential than regulation; to improve safety the ways in which this knowledge exists and flows within the system need to be understood (Pink, et al. in press).

The value of avoiding assumption, imagination, and initiative are all traits of adaptive safety which could be adopted within construction. It could be possible for construction employees to develop resilience even in an industry where the structure and financial constraints do not support resilience at an organisational level. A research agenda is presented in section 4 to outline how this could be achieved. Table 3 lists the employee-centred aspects of the adaptive 
age, whether they arose from HRO or RE, and summarises the positive and negative points from the evaluation of their potential application in construction. 
Table 3 - Summary of barriers and opportunities for applying adaptive employee principles in construction

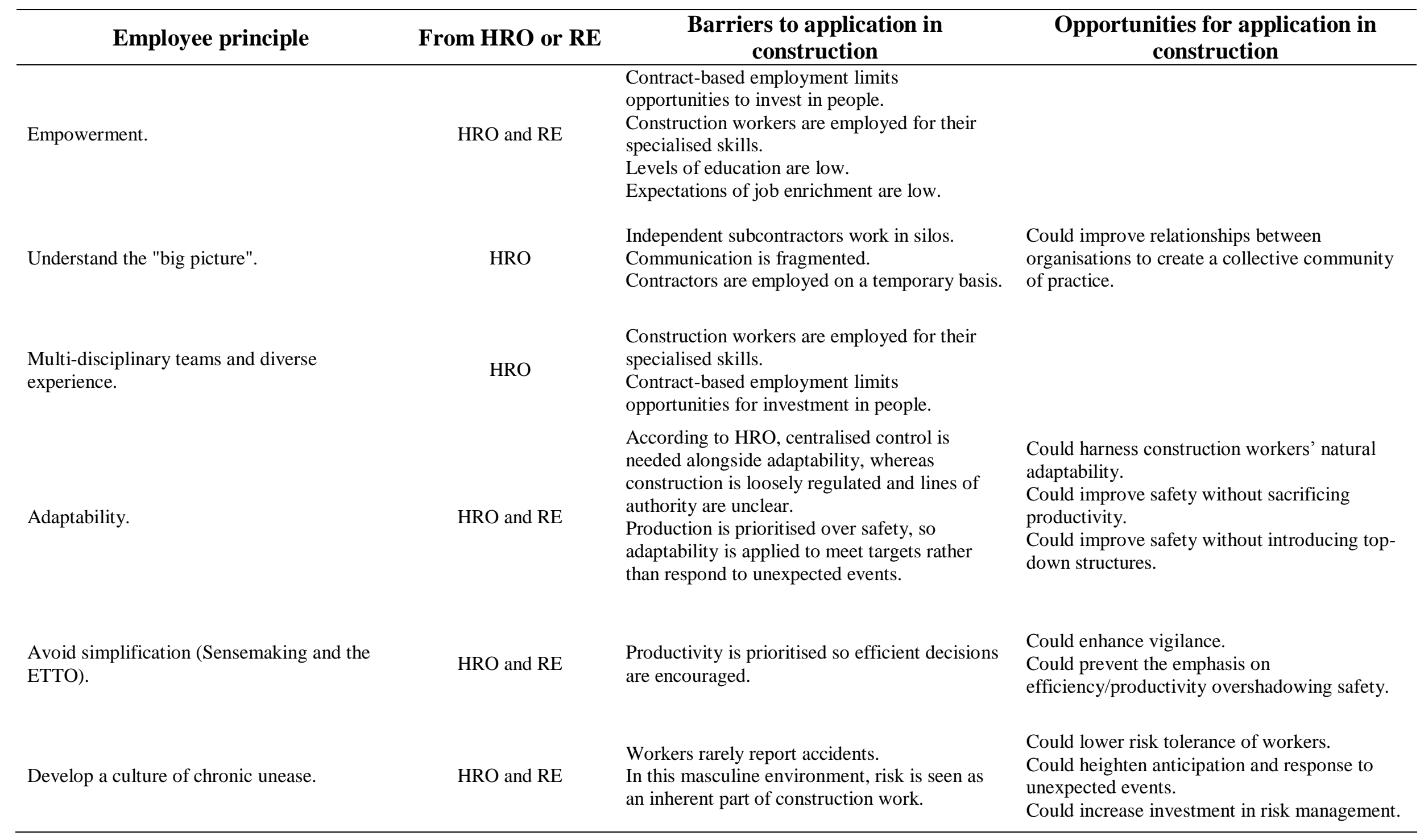




\section{Research Agenda}

For construction to embrace adaptive safety, in light of this evaluation the following areas of research show the most promise and should be made the focus of further research in both construction safety and the adaptive age of safety.

As many of the difficulties incorporating adaptive safety into construction hinge on construction's unique nature as a fragmented and dynamic industry, there is a need to rethink how an understanding of the 'big picture' can be supported in a temporary project formed from a network of organisations. There are examples of high-profile construction megaprojects where systems integration has been successful (Davies, et al. 2009, Bolt, et al. 2012) but this needs to become the norm across the industry in both large and small projects. Opportunities should be sought to learn from these successful megaprojects to create temporary yet well integrated project-based organisations as a basis for adaptive safety.

This review has also brought to light new ways accidents in the construction industry could be reframed to change the way they are approached. Hollnagel's (2009) theory of accidents as a result of drifting performance and functional resonance offers an alternative to the 'root cause' model which contributes to the culture of blame surrounding accidents. Models of drift could be well suited to temporary and dynamic construction organisations (Kreiner, 1995) and need further investigation in this context. Other ideas which could enhance and develop construction's risk management strategy include increasing focus on responding to the present - thus reducing reliance on past experience, which can be inconsistent in a temporary organisation, to inform safety policy - and using a safety-II approach to increase investment in maintaining everyday performance as opposed to preventing accidents.

Finally, the adaptive age's theories about individuals' capacity to anticipate and respond to risk present an opportunity for construction to change at an employee-centred level, reducing accidents without challenging the structure and nature of the industry. Construction workers' have an ability to work around problems, a valuable asset to resilience if it can be ensured it is exercised for safety as well as productivity. There is potential for construction to adapt theories of safety imagination or chronic unease and find ways to develop these traits within workers and heighten vigilance. 


\section{Conclusions}

This review presents a challenge for both construction OSH and the HRO and RE communities. Exploring the two side-by-side, has underlined the disconnect between OSH and systems safety, and the differences between HRO and RE. Further research is needed to understand how construction can reprioritise in order to adopt adaptive safety approaches, and how HRO and RE can be extended and adapted to suit a network of subcontractors and temporary projects.

The Adaptive age requires management commitment, sensitivity to the frontline, prioritisation of safety, empowerment of employees, and a just culture; thus, it seems impossible to apply in an industry where contracting is ubiquitous, and investment in people is limited by the constrained budget and uniqueness of projects. These contrasts are summarised in Table 4.

Table 4 - Summary of contrasts between the adaptive age and construction

\begin{tabular}{|c|c|c|}
\hline & $\begin{array}{c}\text { Characteristics of the } \\
\text { adaptive age }\end{array}$ & Characteristics of construction \\
\hline \multirow{4}{*}{ Structure } & Tightly coupled and complex & Loosely coupled \\
\hline & $\begin{array}{l}\text { Empowered, multi-disciplinary } \\
\text { teams }\end{array}$ & Sub-contractors paid per task \\
\hline & Permanent organisations & Transient projects \\
\hline & $\begin{array}{l}\text { Strong hierarchy of control } \\
\text { (HRO only) }\end{array}$ & $\begin{array}{l}\text { Independent, local decision } \\
\text { making }\end{array}$ \\
\hline \multirow{4}{*}{ Organisation } & $\begin{array}{l}\text { Able to build in contingency } \\
\text { resources }\end{array}$ & $\begin{array}{l}\text { Vulnerable to economic } \\
\text { pressure }\end{array}$ \\
\hline & Safety is prioritised & $\begin{array}{l}\text { Production targets are } \\
\text { prioritised over safety }\end{array}$ \\
\hline & Open to change & Rejects innovation \\
\hline & A just culture & Low levels of reporting \\
\hline \multirow{2}{*}{ Accidents } & $\begin{array}{c}\text { Accidents affect } 3^{\text {rd }} \text { and } 4^{\text {th }} \\
\text { party victims }\end{array}$ & Personal injury accidents \\
\hline & Media attention & $\begin{array}{c}\text { Accidents rarely reported in the } \\
\text { news }\end{array}$ \\
\hline \multirow[b]{2}{*}{ Individuals } & Sensitive to failure & Low risk perception \\
\hline & $\begin{array}{l}\text { Employees understand the "big } \\
\text { picture" }\end{array}$ & $\begin{array}{l}\text { Employees work independently } \\
\text { in silos }\end{array}$ \\
\hline
\end{tabular}

Moreover, considering $\mathrm{HRO}$ and RE in isolation, there are further barriers to their application in construction. HRO uses multi-disciplinary teams to diversify skills and experience, while 
construction workers are employed for their highly-specialised skills and work in silos, and $\mathrm{RE}$ - despite being more open-minded about the approach - relies on experience to inform how an organisation invests in developing resilience, a long-term strategy difficult to implement in temporary projects.

Table 5 summarises the principles of the adaptive age which offer the greatest opportunities for improving safety in construction, providing the barriers can be overcome. The novel approach to risk management and the employee-centred aspects of resilience show the most potential.

Table 5 - Summary of opportunities for construction from the adaptive age

\begin{tabular}{|c|c|c|}
\hline Approach & Origin & Opportunity for construction \\
\hline \multirow{3}{*}{ Risk management } & RE & $\begin{array}{l}\text { Understand that failures emerge from performance } \\
\text { adaptations to cope under pressure to reduce the } \\
\text { propensity for blame. }\end{array}$ \\
\hline & $\mathrm{RE}$ & $\begin{array}{l}\text { Focus on everyday performance to strengthen the system } \\
\text { against accidents and reduce the propensity for blame. }\end{array}$ \\
\hline & $\mathrm{HRO}$ & $\begin{array}{l}\text { Focus on the present when responding to the unexpected } \\
\text { to reduce the requirement for long-term plans and } \\
\text { learning from experience. }\end{array}$ \\
\hline \multirow{5}{*}{ Employee-centred } & $\mathrm{HRO}$ & $\begin{array}{l}\text { Enhance workers' understanding of the "big picture" to } \\
\text { build relationships between subcontractors and prevent } \\
\text { silo working. }\end{array}$ \\
\hline & $\mathrm{HRO}$ and RE & $\begin{array}{l}\text { Encourage adaptability among the workforce to support a } \\
\text { resilient response. }\end{array}$ \\
\hline & & \\
\hline & HRO and RE & $\begin{array}{l}\text { Develop a culture of chronic unease among employees to } \\
\text { lower their tolerance to risk. }\end{array}$ \\
\hline & HRO and RE & $\begin{array}{l}\text { Avoid simplifying unexpected events to maintain a } \\
\text { vigilant and sceptical attitude. }\end{array}$ \\
\hline Organisational & $\mathrm{RE}$ & $\begin{array}{l}\text { Cultivate resilience in a way that is appropriate to the } \\
\text { unique context of each organisation. }\end{array}$ \\
\hline
\end{tabular}

At present, construction workers' "spontaneous resilience" is channelled towards productivity rather than safety because their risk perception is low. Conventional safety measures may have had limited success because the safer an environment feels the more risks people are willing to make (Wilde, 1982), but developing 'chronic unease' or safety imagination could help lower tolerance to risks by contextualising others' accidents, and imagining ways things could fail; this could encourage individuals to act resiliently without needing to adopt top- 
down structures. As construction workers see risk as an integral part of their work (Swuste et al., 2012), intervening to lower their tolerance of risk presents a viable way to improve safety.

The authors have focussed on construction as a domain for this research; however, the findings could be applicable to other hazardous but not safety-critical sectors such agriculture, fisheries, forestry and mining which share organisational characteristics with construction.

\section{Acknowledgement}

The authors would like to thank the two reviewers and the editors from Safety Science for their constructive comments on the earlier draft of this paper. 


\section{References}

Adamski, A.J., Westrum, R.J., 2003. Requisite Imagination: The Fine Art of Anticipating What Might Go Wrong, in: Hollnagel, E. (Ed.), Handbook of Cognitive Task Design. Lawrence Erlbaum Associates, Inc., Mahwah, NJ.

Amalberti, R., 2006. Optimum System Safety and Optimum System Resilience: Agnostic or Antagonistic Concepts?, in: Hollnagel, E., Woods, D.D., Levenson, N. (Eds.), Resilience Engineering: Concepts and Precepts. Ashgate Publishing Limited, Aldershot, UK.

Aulich, T., 2013. The role of effective communication in the construction Industry: A guide for education and health clients. J. Constr. Econ. Build. 13, 92-101.

Bhamra, R., Dani, S., Burnard, K., 2011. Resilience: the concept, a literature review and future directions. Int. J. Prod. Res. 49, 5375-5393. doi:10.1080/00207543.2011.563826

Bolt, H.M., Haslam, R., Gibb, A.G.F., Waterson, P., 2012. Pre-conditioning for success: characteristics and factors ensuring a safe build for the Olympic Park. London: Health and Safety Executive. Research Report RR955.

Borys, D., Else, D., Leggett, S., 2009. The fifth age of safety: The adaptive age? J. Heal. Saf. Res. Pract. 1, 19-27.

Brown, T., Hanlon, M., 2014. In the Interests of Safety. Sphere, London, UK.

Burnard, K., Bhamra, R., 2011. Organisational resilience: development of a conceptual framework for organisational responses. Int. J. Prod. Res. 49, 5581-5599. doi:10.1080/00207543.2011.563827

Burns, T., Stalker, G.M., 1961. The management of innovation. Tavistock, London, UK.

Chinowsky, P., Molenaar, K., Realph, A., 2007. Learning organizations in construction. J. Manag. Eng. 23, 27-34. doi:10.1016/(ASCE)0742-597X

Clegg, S., Kreiner, K., 2014. Fixing concrete: inquiries, responsibility, power and innovation. Constr. Manag. Econ. 32, 262-278. doi:10.1080/01446193.2013.848996

Cook, R.I., Woods, D.D., 2006. Distancing Through Differencing: An Obstacle to Organisational Learning Following Accidents, in: Hollnagel, E., Woods, D.D., Levenson, N. (Eds.), Resilience Engineering: Concepts and Precepts. Ashgate Publishing Limited, Aldershot, 329-338.

Davies, A., Gann, D., Douglas, T., 2009. Innovation in megaprojects: systems integration at london heathrow terminal 5. Calif. Manag. Rev. 51. 101-125.

Dekker, S.W.A., 2015. Ergonomics, Accountability and Complexity, in: Sharples, S., Shorrock, S., Waterson, P. (Eds.), Contemporary Ergonomics and Human Factors 2015. Taylor \& Francis Ltd, Daventry, UK, 21-27. 
Dekker, S.W.A., 2014. The bureaucratization of safety. Saf. Sci. 70, 348-357. doi:10.1016/j.ssci.2014.07.015

Dekker, S.W.A., 2006. Resilience Engineering: Chronicling the Emergence of Confused Concensus, in: Hollnagel, E., Woods, D.D., Levenson, N. (Eds.), Resilience Engineering: Concepts and Precepts. Ashgate Publishing Limited, Aldershot, 77-90.

Dubois, A., Gadde, L.-E., 2002. The construction industry as a loosely coupled system: implications for productivity and innovation. Constr. Manag. Econ. 20. 621-631. doi:10.1080/01446190210163543

DuPont, 2015. The DuPont Bradley Curve. http://www.dupont.co.uk/products-andservices/consulting-services-process-technologies/brands/sustainable-solutions/subbrands/operational-risk-management/uses-and-applications/bradley-curve.html [Accessed 29/05/2015].

Flin, R., 2006. Erosion of Managerial Resilience: From VASA to NASA, in: Hollnagel, E., Woods, D.D., Levenson, N. (Eds.), Resilience Engineering: Concepts and Precepts. Ashgate Publishing Limited, Aldershot, 223-233.

Flyvbjerg, B., 2014. What You Should Know About Megaprojects and Why: An Overview. Proj. Manag. J. 45, 6-19. doi:10.1002/pmj.21409

Fruhen, L.S., Flin, R.., McLeod, R., 2013. Chronic unease for safety in managers: a conceptualisation. J. Risk Res. 17, 969-979. doi:10.1080/13669877.2013.822924

Glendon, A.I., Clarke, S., McKenna, E., 2006. Human Safety and Risk Management, 2nd ed. CRC Press, Boca Raton, FL.

Haddon-Cave, C., 2009. The Nimrod Review. London.

Hale, A., Heijer, T., 2006a. Is Resilience Really Necessary? The Case of Railways, in:

Hollnagel, E., Woods, D.D., Levenson, N. (Eds.), Resilience Engineering: Concepts and Precepts. Ashgate Publishing Limited, Aldershot, 125-149.

Hale, A., Heijer, T., 2006b. Defining Resilience, in: Hollnagel, E., Woods, D.D., Levenson, N. (Eds.), Resilience Engineering: Concepts and Precepts. Ashgate Publishing Limited, Aldershot, 35-41.

Hale, A.R., Hovden, J., 1998. Management and culture: the third age of safety. A review of approaches to organisational aspects of safety health and environment., in: Williamson, A., Feyer, A.-M. (Eds.), Occupational Injury: Risk, Prevention and Intervention. CRC Press, London, 129-167.

Haslam, R.A., Hide, S.A., Gibb, A.G.F., Gyi, D.E., Pavitt, T., Atkinson, S., Duff, A.R., 2005. Contributing factors in construction accidents. Appl. Ergon. 36, 401-15. doi:10.1016/j.apergo.2004.12.002

Health and Safety at Work etc. Act 1974, SI 1974/1439 
Herzberg, F., 1987. One more time: How do you motivate employees? Harv. Bus. Rev. 65, $109-120$.

Hinze, J., Devenport, J.N., Giang, G., 2006. Analysis of Construction Worker Injuries That Do Not Result in Lost Time. J. Constr. Eng. Manag. 132, 321-326. doi:10.1061/(ASCE)0733-9364(2006)132:3(321)

Hollnagel, E., 2014. Safety-I and Safety-II: The Past and Future of Safety Management. Ashgate Publishing Limited, Farnham, UK.

Hollnagel, E., Sundström, G., 2006. States of Resilience, in: Hollnagel, E., Woods, D.D., Levenson, N. (Eds.), Resilience Engineering: Concepts and Precepts. Ashgate Publishing Limited, Aldershot, 339-322.

Hollnagel, E., Woods, D.D., 2006. Epilogue: Resilience Engineering Precepts, in: Hollnagel, E., Woods, D.D., Levenson, N. (Eds.), Resilience Engineering: Concepts and Precepts. Ashgate Publishing Limited, Aldershot, 347-357.

Hollnagel, E., 2009. The ETTO Principle: Efficiency-Thoroughness Trade-Off. Ashgate Publishing Limited, Aldershot, UK.

Hollnagel, E., 2008. Resilience Engineering in a Nutshell, in: Hollnagel, E., Nemeth, C.P., Dekker, S.W.A. (Eds.), Relilience Engineering Perspectives, Volume 1: Remaining Sensitive to the Possibility of Failure. Ashgate Publishing Limited, Aldershot, UK.

Hollnagel, E., Fujita, Y., 2013. The Fukushima Disaster - Systemic Failures as the Lack of Resilience. Nucl. Eng. Technol. 45, 13-20.

Hollnagel, E., Woods, D.D., Levenson, N., 2006. Resilience Engineering: Concepts and Precepts. Ashgate Publishing Limited, Aldershot, UK.

Horne, J.F., Orr, J.E., 1998. Assessing behaviours that create resilient organizations. Employ. Relat. Today 24, 29-40.

House of Commons, 2015. Blacklisting in Employment: Final Report. London.

HSE, 2014. Health and Safety in Construction in Great Britain, 2014.

HSE, 2011. High reliability organisations: A review of the literature. Buxton, UK.

Hudson, P., 2007. Implementing a safety culture in a major multi-national. Saf. Sci. 45, 697722. doi:10.1016/j.ssci.2007.04.005

Kasperson, R.E., Renn, O., Slovic, P., Brown, H.S., Emel, J., Goble, R., Kasperson, J.X., Ratick, S., 1988. The Social Amplification of Risk: A Conceptual Framework. Risk Anal. 8, 177-187. doi:10.1111/j.1539-6924.1988.tb01168.x

Khosravi, Y., Bastani, H., 2014. Factors Influencing Unsafe Behaviors and Accidents on Construction Sites : A Review. Int. J. Occup. Saf. Ergon. 20, 111-125. 
Kreiner, K., 2009. Learning and imagination in construction, in: Procs 25th Annual ARCOM Conference, 7-9 September 2009, Nottingham, UK,. 135-144.

Kreiner, K., 1996. In search of relevance: Project management in drifiting environments. Scandanavian J. Manag. 11, 335-346.

Lindebaum, D., Fielden, S., 2010. 'It's good to be angry': Enacting anger in construction project management to achieve perceived leader effectiveness. Hum. Relations 64, $437-$ 458. doi:10.1177/0018726710381149

Lingard, H., Rowlinson, S., 2005. Occupational Health and Safety in Construction Project Management. Spon Press, Oxon, UK.

Mallack, L., 1998. Putting organisational resilience to work. Ind. Manag. 40, 8-13.

Manu, P., Ankrah, N., Proverbs, D., Suresh, S., 2013. Mitigating the health and safety influence of subcontracting in construction: The approach of main contractors. Int. J. Proj. Manag. 31, 1017-1026. doi:10.1016/j.ijproman.2012.11.011

McDonald, N., 2006. Organisational Resilience and Industrial Risk, in: Hollnagel, E., Woods, D.D., Levenson, N. (Eds.), Resilience Engineering: Concepts and Precepts. Ashgate Publishing Limited, Aldershot, pp. 155-179.

NIOSH. 2011. Construction Safety and Health. http://www.cdc.gov/niosh/topics/construction/ [Accessed 6/7/2016]

olde Scholtenhuis, L.L., Dorée, A.G., 2014. High reliability organizing at the boundary of the CM domain. Constr. Manag. Econ. 32, 658-664. doi:10.1080/01446193.2014.913801

Perrow, C., 1984. Normal Accidents: Living with High Risk Technologies. Basic Books, New York.

Perrow, C., 1967. A framework for the comparative analysis of organisations. Am. Sociol. Rev. 32, 194-208.

Pidgeon, N., O'Leary, M., 2000. Man-made disasters: why technology and organizations (sometimes) fail. Saf. Sci. 34, 15-30. doi:10.1016/S0925-7535(00)00004-7

Pidgeon, N.F., 2010. Systems thinking, culture of reliability and safety. Civ. Eng. Environ. Syst. 27, 211-217. doi:10.1080/10286608.2010.482660

Pink, S., Waterson, P., Dainty, A.R.J., Cheyne, A.J.T., Haslam, R.A., Gibb, A.G., Morgan, J., Hartley, R., Finneran, A.M., Bust, P. [In Press]. Interdisciplinary research for occupational safety and health knowledge. Policy pract. Health saf.

Price, A.D.F., Bryman, A., Dainty, A.R.J., 2004. Empowerment as a Strategy for Improving Construction Performance. Leadersh. Manag. Eng. 4, 27-37. doi:10.1061/(ASCE)15326748(2004)4:1(27)

Reason, J., 2000. Human Error: Models and Management. Br. Med. J. 320, 768-770. 
Reason, J., 1997. Managing the Risks of Organisational Accidents. Ashgate Publishing Limited, Farnham, UK.

Roberts, K.H., Rousseau, D.M., 1989. Reasearch in nearly failure-free, high reliability organisations: Having the bubble. IEEE Trans. Eng. Manag. 36, 139-139.

Safe Work Australia. 2013. Construction Industry Profile. http://www.safeworkaustralia.gov.au/sites/swa/statistics/work-relatedfatalities/pages/worker-fatalities [Accessed 6/7/2016]

Stringer, J., 1967. Operational Research for Development. J. Oper. Res. Soc. 18, 105-120. doi:10.1057/palgrave.jors.2600047

Sutcliffe, K.M., Vogus, T.J., 2003. Organizing for Resilience, in: Cameron, K.S., Dutton, J.E., Quinn, R.E. (Eds.), Positive Organizational Scholarship: Foundations of a New Discipline. Berrett-Koehler Publishers, Inc., San Francisco, CA, pp. 94-110.

Swuste, P., Frijters, A., Guldenmund, F., 2012. Is it possible to influence safety in the building sector? Saf. Sci. 50, 1333-1343. doi:10.1016/j.ssci.2011.12.036

Tamuz, M., Harrison, M.I., 2006. Improving safety in hospitals: Contributions of high reliability theory and normal accident theory. Heal. Res. Educ. Trust 41, 1654-1673.

Taylor, F.W., 1911. The Principles of Scientific Management. Harper \& Brothers, London, UK.

The Guardian, 2015. Two years after Rana Plaza, have conditions improved in Bangladesh's factories? https://www.theguardian.com/sustainable-business/2015/apr/24/bangladeshfactories-building-collapse-garment-dhaka-rana-plaza-brands-hm-gap-workersconstruction. [Accessed 24/04/2015]

Van der Molen, H.F., Lehtola, M.N.M., Lappalainen, J., Hoonakker, P.L.T., Hsiao, H., Haslam, R., Hale, A.R., Frings-dresen, M.H.W., Verbeek, J.H., H, V.J., 2012. Interventions to prevent injuries in construction workers. Cochrane database Syst. Rev. 2012, Issue 12. Art. No.: CD006251. DOI: 10.1002/14651858.CD006251.pub3.

Vogus, T.J., Sutcliffe, K.M., 2007. The safety organising scale: Development and validation of a behavioural measure of safety culture in hospital nursing units. Med. Care 45, 4654.

Walsh, P., 2015. Management of Complex Projects. Presentation at Loughborough University. $26^{\text {th }}$ April.

Waterson, P., Robertson, M.M., Cooke, N.J., Militello, L., Roth, E., Stanton, N.A., 2015. Defining the methodological challenges and opportunities for an effective science of sociotechnical systems and safety. Ergon. 58, 1-35. doi:10.1080/00140139.2015.1015622

Weick, K.E., Sutcliffe, K.M., 2007. Managing the Unexpected: Resilient Performance in an Age of Uncertainty, 2nd ed. Wiley. 
Weick, K.E., Sutcliffe, K.M., Obstfeld, D., 2012. Organizing and the Process of Sensemaking Org. Sci. 16, 409-421.

Weick, K.E., Sutcliffe, K.M., Obstfeld, D., 2008. Organizing for high reliability: Processes of collective mindfulness, in: Boin, A. (Ed.), Crisis Management. Sage Publications, Ltd., Thousand Oaks, CA, pp. 31-66.

Westrum, R.J., 1991. Cultures with Requisite Imagination, in: Wise, J., Stager, P., Hopkin, J. (Eds.), Verification and Validation in Complex Man-Machine Systems. Springer, New York.

Wilde, G.J.S., 1982. The Theory of Risk Homeostasis: Implications for Safety and Health. Risk Anal. 2, 209-225. doi:DOI: 10.1111/j.1539-6924.1982.tb01384.x

Wilson, J.R., 2014. Fundamentals of systems ergonomics/human factors. Appl. Ergon. 45, 513. doi:10.1016/j.apergo.2013.03.021

Wilson, J.R., 2012. Fundamentals of systems ergonomics. Work, 41, Suppl. 1, 3861-8. doi:10.3233/WOR-2012-0093-3861

Woods, D.D., 2006. Essential Characteristics of Resilience, in: Hollnagel, E., Woods, D.D., Levenson, N. (Eds.), Resilience Engineering: Concepts and Precepts. Ashgate Publishing Limited, Aldershot, 21-33.

Woods, D.D., Hollnagel, E., 2006. Prologue: Resilience Engineering Concepts, in: Hollnagel, E., Woods, D.D., Levenson, N. (Eds.), Resilience Engineering: Concepts and Precepts. Ashgate Publishing Limited, Aldershot, 1-6.

Wrethall, J., 2006. Properties of Resilient Organisations: An Initial View, in: Hollnagel, E., Woods, D.D., Levenson, N. (Eds.), Resilience Engineering: Concepts and Precepts. Ashgate Publishing Limited, Aldershot, 275-287.

Zhou, Z., Goh, Y.M., Li, Q., 2015. Overview and analysis of safety management studies in the construction industry. Saf. Sci. 72, 337-350. doi:10.1016/j.ssci.2014.10.006

Zohar, D., 2010. Thirty years of safety climate research: reflections and future directions. Accid. Anal. Prev. 42, 1517-22. doi:10.1016/j.aap.2009.12.019 